\title{
The influence of dexmedetomidine on opioid consumption in radical prostatectomy
}

\author{
Corresponding author: \\ Alenka Spindler-Vesel \\ Department of Anaesthesiology and Surgical Intensive Therapy \\ University Medical Centre Ljubljana \\ Zaloška 7, Ljubljana, Slovenia \\ E-mail: alenka.spindler@guest.arnes.si
}

KSENIJA OGRIČ, NEVA POŽAR-LUKANOVIĆ, MATEJ JENKO, MAJA ŠOŠTARIČ, ALENKA SPINDLER-VESEL

Department of Anaesthesiology and Surgical Intensive Therapy, University Medical Centre Ljubljana, Ljubljana, Slovenia

\section{ABSTRACT}

Objective. Multimodal analgesia and analgesics with different modes of action can reduce perioperative opioid demand and their undesirable side effects.

In our study we presumed that patients anesthetised with additional perioperative dexmedetomidine infusion, during radical prostatectomy, would need less opioids during and after surgery compared to the control group.

Materials and methods. 40 patients, $18-80$ years of age, ASA class 1-3 (American Society of Anesthesiologists), scheduled for radical prostatectomy, were included in the study. Patients were randomly divided into two groups (20 pts in each group). In both groups, fentanyl in repeated boluses was used as an analgesic; in the studied group, an additional infusion of dexmedetomidine $(0.3 \mu \mathrm{g} / \mathrm{kg} / \mathrm{h})$ was started with intravenous line insertion and continued until the beginning of wound closure. Analgesic consumption during the operation, in the post-anaesthesia care unit, in the Intensive Care Unit on the day of the operation and on the first postoperative day was recorded.

Results. The patients with perioperative dexmedetomidine infusion were slightly younger $(p=0.007)$, also the duration of their surgery was shorter $(p=0.05)$. Differences in opioid consumption between the groups were not found. Also, pain assessment, by visual analogue scale (VAS) after $12,18,24,30,36$ and 42 hours, was not statistically different between groups.

Conclusion. In our study, perioperative dexmadetomidine did not reduce periand postoperative opioid consumption. Also, undesirable dexmedetomidine side effects, such as bradycardia and hypotension, were not observed.

Key words: dexmedetomidine, radical prostatectomy

\section{INTRODUCTION}

Radical prostatectomy is one of the extensive urological procedures associated with strong postoperative pain and a hormonal and metabolic stress response, which can lead to cardiovascular complications, increased occurrence of postoperative paralytic ileus, weakening of the immune response, and changes in carbohydrate and protein metabolism. (1) Optimal perioperative pain management is therefore necessary to inhibit injury triggered pain transfer and reduce the autonomous and somatic pain response. (2)

For postoperative analgesia, an epidural catheter can be used. If there are contraindications or if an epidural catheter cannot be inserted, continuous intravenous infusion of piritramide (patient controlled analgesia, PCA) can be used. $(3,4)$ Epidural analgesia reduces the endocrine and metabolic stress response, facilitates early gut mobility, decreases wound infections and postoperative respiratory complications. $(3,5-9)$

Given that epidural catheter insertion is an invasive method associated with complications, and that prostatic cancer patients are older, often with comorbidites, degenerative spine changes and on anticoagulants, this method is often avoided. (10) Only opioid based pain relief is associated with adverse reactions (insufficient breathing, nausea, vomiting, constipation, ileus, drowsiness); also, acute tolerance to opioids may develop intraoperatively. (11-13) Multimodal analgesia is the most appropriate method for postoperative pain relief after radical prostatectomy. Pain relief is more effective and opioid side effects are minimized. (2) Combination of opioids, nonopioid analgesics and analgesics with a different mode of action, dexmedetomidine, reduce opioid consumption and their side effects during and after surgery. (14- 21)
Dexmedetomidine binds onto a2 adrenergic receptors in the locus ceruleus and posterior horns of the spinal cord. It also inhibits the transfer of pain stimulus and reduces the release of norepinephrine. It acts simpaticolitically and therefore reduces mean arterial pressure and heart rate. It also works as an analgesic, hypnotic and anxiolytic drug, and does not inhibit breathing. $(15-18,22)$

Due to the analgesic effect of dexmedetomidine, the need for additional opioids is reduced, there is less breathing depression, nausea and vomiting, bowel function is less affected and recovery is faster. $(15,19-21)$ Dexmedetomidine acts also as an antiinflammatory agent. It inhibits the sympathetic nervous system and stimulates the parasympathetic nervous system, which reduces peripheral proinflammatory cytokine secretion. $(23,24,26)$

The aim of our study was to find out if an intraoperative dexmedetomidine infusion reduces the consumption of opioid analgesics and to study the side effects during and after radical prostatectomy.

\section{MATERIALS AND METHODS}

\section{Subjects}

This prospective study included 40 patients, aged 18 to 80 years, classified according to the American Society of Anaesthesiologists (ASA) into groups 1-3, scheduled for radical prostatectomy.

Prior to the operation, patients gave their signed consent for participation in the study and for anaesthesia and surgery. The study protocol was approved by the Medical Ethics Committee of the Republic of Slovenia, at the Ministry of Health of the Republic of Slovenia (KME 54/07/15).

Patients with allergies to a 2 agonists, uncontrolled arterial hypertension, the presence of a 2 nd or 3rd degree AV block and 
without signed consent to participate, were excluded from the study.

Patients were randomly allocated into two groups, depending on the type of analgesia during the operation. 20 patients were enrolled in each group. During the operation, patients from both groups received fentanyl in repeated doses. Patients in the studied group had an intravenous infusion of dexmedetomidine started at the time of intravenous line insertion until the beginning of surgical wound closure. Consumption of opioids and other analgesics was recorded at the end of surgery and on day 1 .

\section{Induction of anaesthesia}

After the insertion of an intravenous line, induction of anaesthesia was performed with fentanyl (1-2 $\mu \mathrm{g} / \mathrm{kg})$ and propofol $(1.5-2.5 \mathrm{mg} / \mathrm{kg})$ or ethomidat $(0.2 \mathrm{mg} / \mathrm{kg})$. For muscle relaxation rocuronium (0.6 $\mathrm{mg} / \mathrm{kg}$ ) was used.

\section{Maintenance of anaesthesia}

Anaesthesia depth was maintained with sevoflurane, depending on the value of the bispectral index (BIS, Vista). BIS was kept in the range suitable for surgical anaesthesia (40-55).

Patients were mechanically ventilated (tidal volume $6-8 \mathrm{ml} / \mathrm{kg}$ ). Normothermia and normocapnia were maintained. Mean arterial pressure was maintained within $\pm 25 \%$ of the basic value. If mean arterial pressure decreased more than $25 \%$ of basic value, vasoactive drugs were used (ephedrine, phenylephrine).

Muscle relaxation was measured with TOF (train of four). Deep muscle block was maintained (TOF 0, posttetanic count, PTC 1-2).

Before the operation, patients were randomised into two groups that varied depending on the analgesia. Prior to the surgical incision, patients from both groups received an intravenous bolus of fentanyl (1-2 $\mu \mathrm{g} / \mathrm{kg}$ ). Additional boluses of fentanyl (1-2 $\mu \mathrm{g} / \mathrm{kg})$ followed according to clinical parameters (increase in heart rate and blood pressure, sweaty skin, dilated pupils). In the studied group, an infusion of dexmedetomidine $(0.3 \mu \mathrm{g} / \mathrm{kg} / \mathrm{h})$ was started after intravenous line insertion and stopped at the beginning of wound closure. During the operation, fentanyl consumption was recorded.

According to the measured TOF value at the end of the operation, muscle block was antagonised with neostigmin $(2.5 \mathrm{mg})$ and atropine (1 mg) or sugamadex $(2 \mathrm{mg} / \mathrm{kg})$. 4. Postoperative period
At the end of the operation all patients received paracetamol (1 g) and an intravenous infusion of piritramide with PCA (piritramide $0.5 \mathrm{mg} / \mathrm{ml}$, infusion rate 0.5 $\mathrm{mg} / \mathrm{h}$, bolus dose $2 \mathrm{mg}$, lock out time 30 minutes). If, in the recovery room or in the intensive care unit VAS was $\geq 3$, patients first received a bolus dose of piritramide from PCA and then, if necessary, an additional bolus of piritramid ( $3 \mathrm{mg}$ ) and paracetamol $(1 \mathrm{~g})$. Consumption of opioids, other analgesics and VAS was evaluated on the day of surgery and on the 1st postoperative day. VAS was recorded also on the 2nd postoperative day.

\section{Statistical analysis}

Our first aim was to investigate the difference in general characteristics between groups with use of dexmedetomidine and without use of dexmedetomidine. Mean and standard deviation were used for description.

Student's t-test was used to compare variables with normal distribution (body weight and body height) while Mann-Whitney U test was used to compare variables that were not normally distributed (age, surgery duration, opioid consumption and other analgesic consumption). Test of normality was made for each observed variable.

Secondly, we investigated the influence of dexmedetomidine infusion, piritramide and paracetamol consumption, surgery duration, intraoperative fentanyl use, body weight and body height, age, patient ASA physical status on VAS after $12 \mathrm{~h}$ with univariate linear regression model.

Finally, we evaluated the influence of dexmedetomidine infusion and postoperative piritramide consumption on VAS (visual analogue scale) in first $42 \mathrm{~h}$, measured every 6 hours. Complete information provided by the longitudinal data was taken into account estimating mixed-effects regression models, calculated by Medplot. (25)

Medplot is an application for dynamic summary and analysis of longitudinal medical data. The application uses linear regression models for the analysis of numerical outcomes and logistic regression models for binary outcomes; a separate model is fitted for each outcome. The repeated measurements for each subject are taken into account using mixed-effects regression models.

$\mathrm{P}$ value of 0.050 was considered statistically significant. Values were corrected for multiple comparison based on the HolmBonferroni adjustment.

Power of the study (effect size) was calcu- lated post hoc. For statistical analysis Medplot, IBM SPSS Statistics 21 (NY, USA) and Gpower (Kiel, Germany) were used.

\section{RESULTS}

Forty patients randomized into two independent groups were included in the study. In Table 1, ASA health status is presented. There was no statistically significant difference in ASA health status among the two groups (Fisher exact probability test, $\mathrm{p}=$ 0.303 , test value 2,390 )

Patients' characteristics and group comparison are shown in Table 2. Patients in the ttest group with intraoperative dexmedetomidine infusion were on average 6 years younger $(\mathrm{p}=0.007$, Mann-Whitney $\mathrm{U}$ test, test statistic 102,50), surgery duration was 16 minutes shorter $(\mathrm{p}=0.050$, MannWhitney U test, test statistic 120,6). There was no difference in opioid consumption among groups.

\section{PAIN ASSESSMENT}

Pain assessment (VAS) in the postoperative period is shown in Figure 1.

Variates used in comparison, and their influence on VAS after 12 hours, are shown in Table 3. Pain assessment after 12 hours was lower in the dexmedetomidine group (linear regression model, $\mathrm{p}=0.042$. See statistical analysis for details.).

VAS values in the postoperative period $(12,18,24,30,36,42$ hours after surgery) were analysed in a mixed regression model for longitudinal comparison. There was no difference among groups in general VAS assessment in 42 postoperative hours (OR 1.19 95\%CI 0.29-4.87, p=0.809). Higher piritramide consumption in recovery was related to higher VAS values in the postoperative period, with a Beta coefficient of 1.39 (95\% CI $1.08-1.780, \mathrm{p}=0.009$ ).

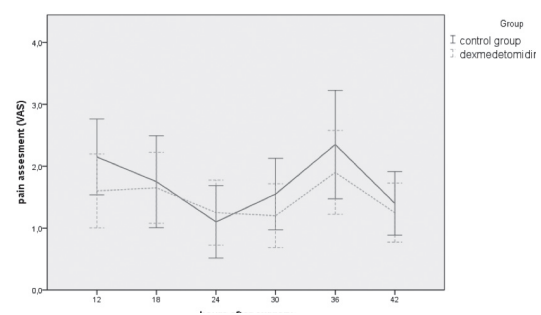

Figure 1. Pain assessment, shown as VAS score, in first 42 hours after surgery. Average and 95\% confidence interval are shown. VAS, visual analogue scale. 
Table 1. ASA health status of included patients.

\begin{tabular}{lllll}
\hline \multicolumn{5}{c}{ Number of patients } \\
\hline & Without use of dexmedetomidine & With intraoperative use of dexmedetomidine & total \\
\hline ASA & 1 & 1 & 0 & 1 \\
& 2 & 12 & 16 & 28 \\
& 3 & 7 & 4 & 11 \\
\hline total & 20 & 20 & 40 & \\
\hline
\end{tabular}

ASA, American Society of Anaesthesiologists.

Table 2. Patients' characteristics.

\begin{tabular}{lll}
\hline Variable & $\begin{array}{l}\text { mean (standard deviation) } \\
\text { without Dexmedetomidine }\end{array}$ & $\begin{array}{l}\text { mean (standard deviation) } \\
\text { Dexmedetomidine group }\end{array}$ \\
\hline Age (years) & $69.2(+7.03)^{*}$ & $63(+7.54)^{*}$ \\
\hline Body weight $(\mathrm{kg})$ & $84.6(+6.66)$ & $83.2(+15.1)$ \\
\hline Body height $(\mathrm{cm})$ & $174.5(+5.64)$ & $173.0(+5.84)$ \\
\hline Intraoperative fentanyl consumption $(\mathrm{mg})$ & $0.48(+0.08)$ & $0.48(+0.09)$ \\
\hline Surgery duration time $($ minutes $)$ & $157(+28)^{* *}$ & $141(+31)^{* *}$ \\
\hline Piritramide consumption in recovery $(\mathrm{mg})$ & $3.37(+3.27)$ & $2.70(+2.67)$ \\
\hline Paracetamol consumption $(\mathrm{g})$ & $1.68(+0.82)$ & $1.90(+1.21)$ \\
\hline Total piritramide consumption $(\mathrm{mg})$ & $31.18(+13.55)$ & $36.87(+15.93)$ \\
\hline
\end{tabular}

${ }^{*} \mathrm{p}=0.007$ (statistically significant $\mathrm{p}$ value)

${ }^{* *} \mathrm{p}=0.050$

Table 3. Influence of variables on VAS after 12 hours (univariate linear regression, see statistical analysis section for details).

\begin{tabular}{lllll}
\hline Variable & Regression coefficient & $\mathbf{9 5 \% C I}$ & & P value \\
\hline Piritramide consumption & 0.006 & -0.043 & 0,055 & 0.820 \\
\hline Paracetamol consumption & 0.753 & -0.105 & 1,611 & 0.085 \\
\hline Surgery duration & -0.009 & -0.035 & 0,016 & 0.466 \\
\hline Intraoperative fentanyl consumption & 0.010 & -8.985 & 9,006 & 0.998 \\
\hline Patient body weight & -0.011 & -0.069 & 0,047 & 0.709 \\
\hline ASA health status & 0.190 & -1.259 & 1,640 & 0.797 \\
\hline Patient age & -0.052 & -0.144 & 0,040 & 0.268 \\
\hline Patient body height & -0.050 & -0.183 & 0.083 & 0.461 \\
\hline Piritramide consumption in recovery & 0.102 & -0.124 & 0.328 & 0.376 \\
\hline Intraoperative use of dexmedetomidine & -1.538 & -3.024 & 0.52 & $0.042^{*}$ \\
\hline
\end{tabular}

* statistically significant $\mathrm{p}$ value

ASA, American Society of Anaesthesiologists; VAS, visual analogue scale.

\section{POWER OF THE STUDY}

Power of the study was evaluated post hoc. Overall piritramide consumption was used in the model simulation. For simulation, Gaussian distribution of parameter was assumed. Significance of 0.05 and power of 0.8 were predicted. Calculated effect size was $\mathrm{d}=0.90$. Difference among dexmedetomidine and test groups in piritramide consumption would be statistically significant if average consumption would differ for $12 \mathrm{mg}$ or more.

\section{DISCUSSION}

Forty patients, scheduled for radical prostatic resection, were involved in our clinical randomized prospective study. They were randomised into two groups, depending on the type of analgesia received during the operation. Intraoperatively, both groups received fentanyl in repeated doses. In the studied group dexmedetomidine infusion was started after insertion of the intravenous line and stopped at the beginning of wound closure. At the time of study completion, we found out that in the dexmedetomidine group patients were younger and operation time was shorter. Otherwise, there were no differences between the two groups in terms of body height, body weight and ASA physical status. During the operation, fentanyl consumption was recorded, and after surgery, piritramide consumption was noted. We did not find any difference between the groups.

So far, few studies have been published which monitor intraoperative opioid 
consumption during simultaneous dexmedetomidine infusion. As in our study, Morgan and colleagues did not find any differences in intraoperative opioid consumption during simultaneous dexmedetomidine infusion (initial bolus $1 \mu \mathrm{g} /$ $\mathrm{kg}$, followed by an infusion of $0.5 \mu \mathrm{g} / \mathrm{kg} / \mathrm{h}$ ). (26) Also, Dong-Jian Ge did not notice reduced intraoperative opioid consumption during simultaneous dexmedetomidine infusion $(0.4 \mu \mathrm{g} / \mathrm{kg} / \mathrm{h})$. (27)

In contrast, reduced intraoperative opioid consumption during simultaneous dexmedetomidine use has been found in both laparoscopic and classical bariatric surgery and also in laparoscopic and classical hysterectomy. $(18,21,28,29)$ In bariatric operations, Gurbert and Bakhames used a single dose of dexmedetomidine $(1 \mu \mathrm{g} / \mathrm{kg}$ or 0.8 $\mu \mathrm{g} / \mathrm{kg}$ ) for induction in anaesthesia, followed by intravenous infusion till the end of the operation $(0.5 \mu \mathrm{g} / \mathrm{kg} / \mathrm{h}$, or $0.4 \mu \mathrm{g} /$ $\mathrm{kg} / \mathrm{h})$. (18)

In laparoscopic and classical gynaecological operations, MC Queen-Shadfar did not find any significant correlation between the dose of dexmedetomidine and intraoperative and postoperative opioid consumption. (28) The same was proven by Tufanogullari, who used different doses of dexmedetomidine, from $0.2 \mu \mathrm{g} / \mathrm{kg}$ up to $0.8 \mu \mathrm{g} / \mathrm{kg}$. In the same study he demonstrated a correlation between the dose of dexmedetomidine and adverse effects of dexmedetomidine on the cardiovascular system, such as hypotension, hypertension and bradycardia. He, therefore, recommended the smallest dose of dexmedetomidine $0.2 \mu \mathrm{g} / \mathrm{kg} / \mathrm{h}$ in order to avoid adverse effects. (22)

In our study, we did not use the initial single dose of dexmedetomidine. There are different opinions regard this topic. Some recommend it, because it probably prolongs dexmedetomidine analgesic effect postoperatively. $(18,20)$ With an initial dexmedetomidine bolus, efficient dexmedetomidine plasma concentration can be achieved at the beginning of the operation. Others avoid a bolus of dexmedetomidine because of possible side effects. $(22,28)$ Ramsay believes that the use of the initial bolus will depend on the length of anaesthesia. (30) An analgesic effect of dexmedetomidine was proven in healthy volunteers. (31) Feld and Hofer success- fully used it in bariatric surgery instead of intraoperative opioids. $(20,32)$ In healthy volunteers,, a bolus of dexmedetomidine had a moderate analgesic effect, in comparison to fentanyl, and was found to be most effective at a dose of $0.5 \mu \mathrm{g} / \mathrm{kg} / \mathrm{h}$. (33) In many studies, the influence of intraoperative dexmedetomidine infusion on postoperative opioid and nonopioid analgesic consumption has been proven. (18- 22,26,27,29,30,34-38) Gubert and Arain found better postoperative analgesia and $66 \%$ lower opioid consumption in the first 48 hours after major abdominal surgery. In both studies patients received a single dose of dexmedetomidine $(1 \mu \mathrm{g} /$ $\mathrm{kg}$ ) at induction of anaesthesia, continued with intraoperative dexmedetomidine infusion $(0.5 \mu \mathrm{g} / \mathrm{kg} / \mathrm{h}) .(18,21,38)$ Some authors believe that the extended analgesic effect of dexmedetomidine, which lasts 24 to 48 hours after surgery, is a result of dexmedetomidine half time, which is 2 to 3 hours. Others are of the opinion that its extended analgesia is due to the anxiolytic and thymoleptic properties of $₫ 2$-agonists, which act on an emotional component of postoperative pain. (18)

Tufanogullari showed that intraoperative dexmedetomidine significantly reduced postoperative opioid consumption and that it does not depend on the dose of dexmedetomidine. (22) It is still not proven weather a bolus dose of dexmedetomidine prolongs postoperative analgesia. (28) Bakhames described decreased opioid consumption on the first postoperative day in patients, who received an induction bolus dose of dexmedetomidine $(0.8 \mu \mathrm{g} / \mathrm{kg} / \mathrm{h})$, continued by intraoperative infusion $(0.4$ $\mu \mathrm{g} / \mathrm{kg} / \mathrm{h}$ ) (21). MC Queen - Shadfar demonstrated reduced postoperative opioid consumption only in the recovery room after classic, but not after laparoscopic hysterectomy, as well. During the operation they used a dexmedetomidine infusion $(0.2-1 \mu \mathrm{g} / \mathrm{kg} / \mathrm{h})$, without the bolus dose. She concluded that after discharge from recovery, opioid consumption in the first 24 hours after surgery was not decreased. (28) Patients operated laparoscopically, needed equal doses of opioids as those after classical surgery. (39)

Patients who received an intraoperative dexmedetomidine infusion, needed a first bolus of opioid 4 to 6 hours later than pa- tients from the placebo group, which took the first dose of analgesic in the first hours after surgery. $(26,36)$

In our study, we demonstrated a lower consumption of opioids during and after surgery in a group of patients who received an intraoperative dexmedetomine infusion. The cause could be the fact that these patients were younger than those in the control group. There is evidence that age affects the need for analgesics and sedatives. (40) But in an analysis of the impact of individual factors on VAS after 12 hours, we were not able to find the impact of age and duration of the operations on the intensity of pain. Biovariability also affects pain. Results could be different if all procedures were to be performed by the same surgeon.

In our study, VAS 12 hours after surgery in the dexmedetomidine group was statistically significantly different from the control group. The effect was not detected in the follow up; it was also too small to significantly change the entire load of pain in the postoperative period. With a larger number of patients in our study or a higher-dose of intraoperative dexmedetomidine in the studied group, we might have demonstrated the impact of dexmedetomidine on opioid consumption throughout the whole postoperative period. Similarly, some studies showed that intraoperative use of dexmedetomidine did not affect the assessment of pain, using VAS, despite the fact that decreased postoperative opioid consumption was demonstrated. $(22,28,38)$

\section{CONCLUSIONS}

In our study, we demonstrated that intraoperative use of dexmedetomidine reduces opioid consumption 12 hours after surgery. We might be able to reduce opioid consumption even during and after surgery, if we included a larger number of patients, more homogeneous groups, an initial bolus dose of dexmedetomidine and/or higher intraoperative dexmedetomidine maintenance dose. Side effects of dexmedetomidine, such as hypotension and bradycardia, were not observed in our study. 
1. Frank E, Sood OP, Torjman M. Postoperative epidural analgesia following radical retropubic prostatectomy. J Surg Oncol 1998;67:11720.

2. Ben-David B, Swanson J, Nelson JB, Chelly JE. Multimodal analgesia for radical prostatectomy provides better analgesia and shortens hospital stay. J Clin Anesth 2007;19:264-8.

3. Liu S, Carpenter RL, Neal JM. Epidural anaesthesia and analgesia. Their role in postoperative outcome. Anaesthesiology 1995;82:1474506.

4. Kietzmann D, Bouillon T, Hamm C, Schwabe K, Schenk H, Gundert-Remy U, Kettler D. Pharmacodynamic modelling of the analgesic effects of piritramide in postoperative patients. Acta Anaesthiol Scand 1997;41:888-94.

5. Stenseth R, Bjella L, Berg EM, Christensen O, Levang OW, Gisvold SE. Thoracic epidural analgesia in aortocoronary bypass surgery II: effects on the endocrine metabolic response. Acta Anaesthesiol Scand 1994;38:384-9.

6. Stevens R, Mikat-Stevens M. Does the anaesthetic technique affect recovery of bowel function after radical prostatectomy? Br J Anaesth 1998;80:551-2.

7. Gruber EM, Tschernko EM, Kritzinger M, Deviatko E, Wisser W, Zurakowski D, Haider W. The effect of thoracic epidural analgesia with bupivacaine $0,25 \%$ on ventilatory mechanics in patient with severe chronic obstructive pulmonary disease. Anaesth Analg 2001;92:1015-9.

8. Jayr C, Thomas H, Rey A, Farhat F, Lasser P, Bourgain JL. Postoperative pulmonary complications: epidural analgesia using bupivacaine and opioids versus parenteral opiods. Anesthesiology 1993;78:666-76.

9. Clark F, Gilbert HC. Regional analgesia in the intensive care unit. Principles and prctice. Crit Care Clin 2001;17:943-66.

10. Freise H, Van Aken HK. Risks and benefits of thoracic epidural anaesthesia. Br J Anaesth 2011;107:859-68.

11. Brook P, Connel J,Pickering T. Basics principles of acute pain. In: Brook P, Connel J, Pickering T, editors. Oxford handbook of pain management, Oxford: Oxford University Press; 2011. p. 3-32.

12. Mastronardi P, Cafiero T. Rational use of opioids. Minerva Anestesiol 2001;67:332-7.

13. Guingnard B, Bossard AE, Coste C, Sessler DI, Lebrault C, Alfonsi P, Fletcher D, Chauvin M. Acute opiod tolerance: intraoperative remifentanil increases postoperative pain and morphine requirement. Anesthesiology 2000;93:407-17.

14. Brodner G, Van Aken H, Hertle L, Fobker M, Von Eckardstein A, Goeters C, et al. Multimodal perioperative management-combinig thoracic epidural analgesia forced mobilization and oral nutrition reduces hormonal and metabolic stress and improves convalescence after major urologic surgery. Anesth Analg 2001;92:1594-600.

15. Venn RM, Bradshaw CJ, Spencer R, Brealey D, Caudwell E, Naughton C, et al. Preliminary UK experience of dexmedetomidine, a novel agent for postoperative sedation in the intensive care unit. Anaesthesia 1999;54:1136-42.

16. Gertler R, Brown HC, Mitchell DH, Silvius EN. Dexmedetomidine: a novel sedative analgesic agent. BUMC Proceedings 2001;14:1321.

17. Arcangeli A, Alo C, Gaspari R. Dexmedetomidine use in general anaesthesia. Current Drug Targets 2009;10:687-95.

18. Gurbert A, Mogol EB, Turker G et al. Intraoperative infusion of dexmedetomidine reduces perioperative analgesic requirements. An J Anaesth 2006;53:646-52.

19. Ramsay MA, Luterman DL. Dexmedetomidine as a total intravenous anesthetic agent. Anesthesiology 2004;101:787-90.

20. Feld JM, Hoffman WE, Stechert MM, Hoffman IW, Ananda RC. Fentanyl or dexmedetomidine combined with desflurane for bariatric surgery. J Clin Anesth 2006;18:24-8.

21. Bakhames HS, El-Halafawy YM, El-Kerdawy HM, Gouda NM, Altemyatt S. Effects of dexmedetomidine in morbidly obese patients undergoing laparoscopic gastric bypass. Middle East J Anesthesiol 2007;19:537-51.

22. Tufanogullari B, White PF, Peixoto MP, Kianpour D, Lacour T, Griffin J, et al. Dexmedetomidine infusion during laparoscopic bariartric surgery: the effect on recovery outcome variables. Anesth Analg 2008;106:1741-8.

23. Kamibayashi T, Maze M. Clinical uses of alpha 2-adrenergic agonists.Anesthesiology 2000;93:1345-9.

24. Kawasaki T, Kawasaki C, Ueki M, Hamada K, Habe K, Sata T. Dexmedetomidine suppreses proinflammatory mediator production in human whole blood in vitro. J Trauma Acute Care Surg 2013;74:1370-5.

25. Ahlin Č, Stupica D, Strle F, Lusa L (2015) medplot: A Web Application for Dynamic Summary and Analysis of Longitudinal Medical Data Based on R. PLoS ONE 10(4): e0121760

26. Taniguchi T, Kidani Y, Kanakura H, Takemoto Y, Yammamoto K. Effects of dexmedetomidine on mortality rate and inflammatory responses to endotoxin induced shock in rats. Crit Care Med 2004;32:1322-6.

27. Morgan LG, Ngai L, Tounou F, Auge M, Tuil O, Chazot T, et al. Dexmedetomidine reduces propofol and remifentanil requirements during bispectral index-guided closed-loop anaesthesia. A double-blind, placebo-controlled trial. Anesth Analg 2014;110:1-18.

28. Dong JG, Qi B, Tang G, Li JY. Intraoperative dexmedetomidine promotes postoperative analgesia and recovery in patients after histerectomy: a double- blind, randomized clinical trial. Sci Rep 2016;6:21514.

29. McQueen-Shadfar L, Megalla SA, White WD, Olufolabi AJ, Jones CA, Habib AS. Impact of intraoperative dexmedetomidine on postoperative analgesia following gynecologic surgery. Curr Med Research Op 2011;27:2091-7.

30. Courtney RJ. Perioperative uses of dexmedetomidine. Anaesthesiaclinics 2016;51:81-96.

31. Ramsay MA. Bariartric surgery: the role of dexmedetomidine. Seminars in Anesthesia, Perioperative Medicine and Pain 2006;25:516.

32. Hall JE, Ulrich DT, Barney JA, Arain SR, Ebert TJ. Sedative, amnestic and analgesic properties of small-dose dexmedetomidine infusions. Anaesth Analg 2000;90:699-705.

33. Hofer RE, Sprung J, Sarr MG, Wedel DJ. Anaesthesia for a patient with morbid obesity dexmedetomidine without narcotics. Canad J Anesth 2005;52:176-80. 
34. Jaakola ML, Salonen M, Lehtinen R, Scheinin H. The analgesic action of dexmedetomidine - a novel $₫ 2$ - adrenoreceptor agonist - in healthy volunteers. Pain 1991;46:281-5.

35. Jung KP, Soon HC, Kun ML, Se HL, Jeong HL, Kwangrae C, et al. Does dexmedetomidine reduce postoperative pain after laparoscopic cholecystectomy with multimodal analgesia? Korean J Anesthesiol 2012;63:436-40.

36. Dong JG, Qi B, Tang G, Li JY. Intraoperative dexmedetomidine promotes postoperative analgesia in patients after abdominal colectomy. Medicine 2015;94:1-5.

37. Jie S, Quing J, Quing S, Tao G, Kui L, Li L. The opiod-sparing effect of intraoperative dexmedetomidin infusion after craniotomy. J Neurosurg Anesthesiol 2015;00:1-7.

38. Yacout AG, Osman HA, Mamdouh HAD, Saleh AH, Mohamed ME. Effect of intravenous dexmedetomidine on some proinflammatory cytokines, stress hormones and recovery profile in major abdominal surgery. Alexandria J Med 2012;48:3-8.

39. Arain SR, Ruchlow RM, Ulrich TD, Ebert TJ. The efficacy of dexmedetomidine versus morphine for postoperative analgesia after major inpatient surgery. Anesth Analg 2004;98:153-8.

40. Nguyen NT, Lee SL, Goldman C, Fleming N, Arango A, Mc Fall R. Comparison of pulmonary function and postoperative pain after laparoscopic versus open gastric bypass a randomized trial. J Am Coll Surg 2001;192:469-76.

41. Jeongmin K, Won OK, Hye BK, Hae KK. Adequate sedation with single-dose dexmedetomidine in patients undergoing transurethral resection of the prostate with spinal anaesthesia: a dose- response study by age group. BMC Anasthesiology 2015;15:17-23. 